\title{
In vitro validation of a self-driving aortic-turbine venous-assist device for Fontan patients
}

Kerem Pekkan, PhD, ${ }^{\text {a }}$ Ibrahim Basar Aka, MSc, ${ }^{\text {a }}$ Ece Tutsak, BS, ${ }^{\text {a }}$ Erhan Ermek, MS, ${ }^{\text {a }}$ Haldun Balim, ${ }^{\mathrm{a}}$ Ismail Lazoglu, $\mathrm{PhD},{ }^{\mathrm{a}}$ and Riza Turkoz, $\mathrm{MD}^{\mathrm{b}}$

\section{ABSTRACT}

Background: Palliative repair of single ventricle defects involve a series of openheart surgeries where a single-ventricle (Fontan) circulation is established. As the patient ages, this paradoxical circulation gradually fails, because of its high venous pressure levels. Reversal of the Fontan paradox requires an extra subpulmonic energy that can be provided through mechanical assist devices. The objective of this study was to evaluate the hemodynamic performance of a totally implantable integrated aortic-turbine venous-assist (iATVA) system, which does not need an external drive power and maintains low venous pressure chronically, for the Fontan circulation.

Methods: Blade designs of the co-rotating turbine and pump impellers were developed and 3 prototypes were manufactured. After verifying the singleventricle physiology at a pulsatile in vitro circuit, the hemodynamic performance of the iATVA system was measured for pediatric and adult physiology, varying the aortic steal percentage and circuit configurations. The iATVA system was also tested at clinical off-design scenarios.

Results: The prototype iATVA devices operate at approximately 800 revolutions per minute and extract up to $10 \%$ systemic blood from the aorta to use this hydrodynamic energy to drive a blood turbine, which in turn drives a mixed-flow venous pump passively. By transferring part of the available energy from the singleventricle outlet to the venous side, the iATVA system is able to generate up to approximately $5 \mathrm{~mm} \mathrm{Hg}$ venous recovery while supplying the entire caval flow.

Conclusions: Our experiments show that a totally implantable iATVA system is feasible, which will eliminate the need for external power for Fontan mechanical venous assist and combat gradual postoperative venous remodeling and Fontan failure. (J Thorac Cardiovasc Surg 2018;156:292-301)

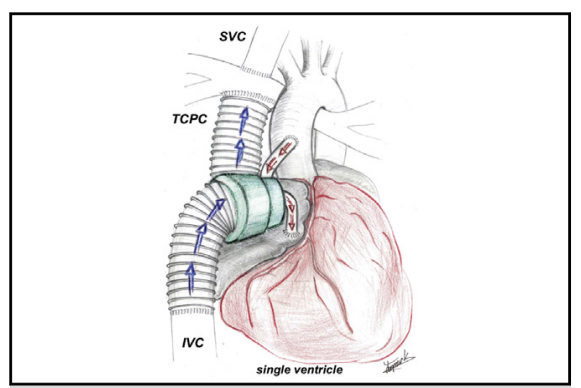

Chronic mechanical venous support driven by an aortic turbine for Fontan patients.

\section{Central Message}

An integrated aortic-turbine venous-assist device that requires no external power can eliminate driveline infections and reverse the detrimental effects of single-ventricle physiology, passively.

\section{Perspective}

For failed Fontan patients with high SVP and persistent hemodynamic decline, the only treatment is cardiac transplantation. A chronic assist device that maintains low SVP can heal at-risk patients well before deteriorating to this terminal state. With low aortic steal, no desaturation, and external drive power, this novel system will impact congenital heart disease management.

See Editorial Commentaries pages 302 and 304.

See Editorial page 289.
From the a Department of Mechanical Engineering, Koç University, Sarıyer, Istanbul, Turkey; and ${ }^{b}$ Department of Cardiovascular Surgery, School of Medicine, Acıbadem University, Istanbul, Turkey.

Funding for this study was provided by the European Union FP7 CIG-293931CardioFluidMechanics, European Research Council Starting Grant 307460, and Scientific and Technological Research Council of Turkey (TUBITAK) 1003 priority-research program grant 115E690 (Principal Investigator: Kerem Pekkan).

Received for publication Sept 26, 2017; revisions received Jan 11, 2018; accepted for publication Feb 8, 2018; available ahead of print April 14, 2018.

Address for reprints: Kerem Pekkan, PhD, Mechanical Engineering Department, Koç University, Rumeli Feneri Campus, Sarıyer, Istanbul, Turkey (E-mail: kpekkan@ ku.edu.tr).

0022-5223

Copyright (C) 2018 by The American Association for Thoracic Surgery. This is an open access article under the CC BY-NC-ND license (http://creativecommons.org/ licenses/by-nc-nd/4.0/)

https://doi.org/10.1016/j.jtcvs.2018.02.088
The Fontan procedure and its subsequent modifications are a set of surgical procedures specifically designed for complex single-ventricle patients in whom a series-circulation is reconstructed by channeling systemic venous return directly to the lungs (around the heart) so that the single-ventricle is filled by fully saturated pulmonary

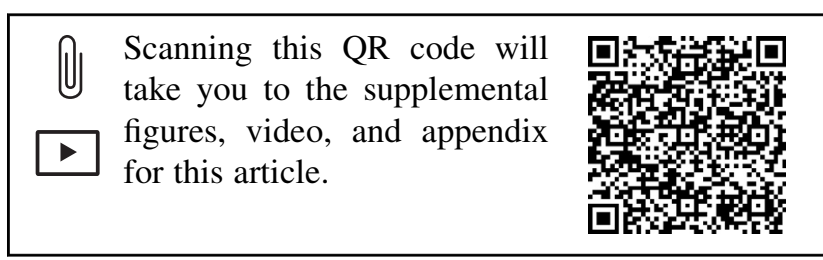




$$
\begin{aligned}
& \text { Abbreviations and Acronyms } \\
& \mathrm{CO}=\text { total cardiac output } \\
& \text { FVAD }=\text { Fontan ventricular assist } \\
& \text { iATVA }=\text { integrated aortic-turbine venous-assist } \\
& \text { system } \\
& \text { IVC = inferior vena cava } \\
& \text { LPM = liters per minute } \\
& \Delta \mathrm{P}=\text { net venous pressure augmentation } \\
& \text { PA = pulmonary artery } \\
& \mathrm{rpm}=\text { revolutions per minute } \\
& \mathrm{SVC}=\text { superior vena cava } \\
& \text { SVP = systemic venous pressure } \\
& \mathrm{TCPC}=\text { total cavopulmonary connection }
\end{aligned}
$$

venous blood, which is then pumped to the body. ${ }^{1-3}$ As would be expected, the initial experience with the Fontan procedure was characterized by the sudden lack of active right-heart pumping of blood into the pulmonary arterial tree, resulting in significant venous congestion, reduced ventricular filling, low cardiac output, and often, death. ${ }^{4-6}$ Despite these physiological challenges, advances in pediatric cardiovascular surgery have resulted in reduced morbidity and mortality in this patient group. ${ }^{7-11}$ This trend has also dramatically increased the number of adult Fontan survivors having severe late complications related to the gastrointestinal system, including feeding disorders, liver dysfunction, protein losing enteropathy, plastic bronchitis, and eventual failed-Fontan states. Although the causes for these complications are multifactorial, chronically high systemic venous pressure (SVP) is widely accepted to be the fundamental problematic factor that results in gradual remodeling in the venous vascular and lymphatic systems. ${ }^{12-14}$ To alleviate this problem, an inferior vena cava (IVC) fenestration is used as a type of pop-off valve for high SVP, but with decreased oxygen saturation, in which novel fenestration flow control mechanisms were introduced. ${ }^{15}$

As an optimum solution for high SVP, the need for venous Fontan ventricular assist (FVAD), ${ }^{16,17}$ erroneously compared with traditional mechanical circulatory assistance, was introduced by de Leval, ${ }^{4,5}$ providing low venous pressure head and high flow rate to address the "Fontan paradox." ${ }^{14}$ Since then, the mechanical univentricle assist has been explored through acute animal models, pioneered by Rodefeld et al, ${ }^{18-20}$ followed by a number of cases, describing initial experience with the available pediatric assist systems in single-ventricle patients. ${ }^{21-27}$ Our earlier work summarized standard singleventricle assist configurations, ${ }^{28-30}$ and also introduced the recently popular ejector pumps for IVC or superior vena cava (SVC) augmentation. ${ }^{31}$ Today, FVADs are designed specifically for the pediatric population using novel impellers with ultra-low blood damage. ${ }^{32}$ Performance characteristics of selected FVAD systems are compared in Table E1. However, the use of FVAD as a long-term therapy with a totally implanted impeller has not been realized with the state-of-the art technology.

For FVAD systems, the need for external power to drive the venous pump unit is a major technological grand challenge. This requirement significantly limits the primary function of FVADs to be implanted for independent use long-term. To address this challenge, we present a novel implantable Fontan assist system that requires no external power and therefore has the potential to passively resolve the Fontan paradox. The device extracts a minimal amount of aortic blood, which is at high systemic pressure head, and uses this available energy to drive an aortic turbine (see Figure 1). In turn, the blood turbine drives a typical mechanical assist device (pump impeller), which supplies the required high-flow and low-pressure venous head through the IVC and/or SVC. The impellers of this new integrated aortic-turbine venous-assist (iATVA) system are connected through a common shaft and rotate at the same speed. This system transfers part of the available aortic energy to the venous site, where it is most needed in the single-ventricle circulation. In this research study we investigated the feasibility of the first-generation iATVA prototypes using our bench-top single-ventricle circulation mock-up circuit, ${ }^{29,33}$ before their detailed mechanical design and planned animal experiments in the near future.

\section{METHODS}

\section{Hydrodynamic Design and Turbomachinery}

A parametric design of the iATVA system was prepared to document its ideal operating ranges and performance capabilities. The design parameters were formulated around the 2 baseline operating conditions, corresponding to the postoperative pediatric (total cardiac output [CO] 3 liters per minute [LPM] and 60\% IVC flow split) and adult Fontan stages (5 LPM with $80 \%$ IVC flow split). For these conditions the hydrodynamic design of 3 iATVA prototypes were completed (see Figure 2 and Table E2). The detailed design process is provided in the section "Turbomachinery Calculations" of Appendix E1.

For the placement of the turbine drainage outlet, 3 alternative locations were considered; common atrium, proximally ligated axillary artery, and distal pulmonary artery (PA), each having different available drive power (see Figure E1). For this research study the turbine was positioned between the aorta and the common atrium (Figure 1 and Figure E1, Configuration 1 ), where the maximum available pressure head between the aortic inlet and turbine outlet is approximately $90 \mathrm{~mm} \mathrm{Hg}$.

\section{Manufacturing and Assembly}

All parts were manufactured by +90 Rapid Prototyping (Istanbul, Turkey), using a Stratasys Connex500 (Stratasys, Eden Prairie, Minn) 3-D printer, except for the bearing. The transparent shrouds and impellers were manufactured with Polyjet-Veroclear and Verowhite resins (Stratasys), respectively. Standard steel bearing (MOS, Istanbul, Turkey), with $5 \times 14 \times 5 \mathrm{~mm}$ dimensions were used. Tight-fitting tolerances were assured for manual assembly of parts by fine polishing. 


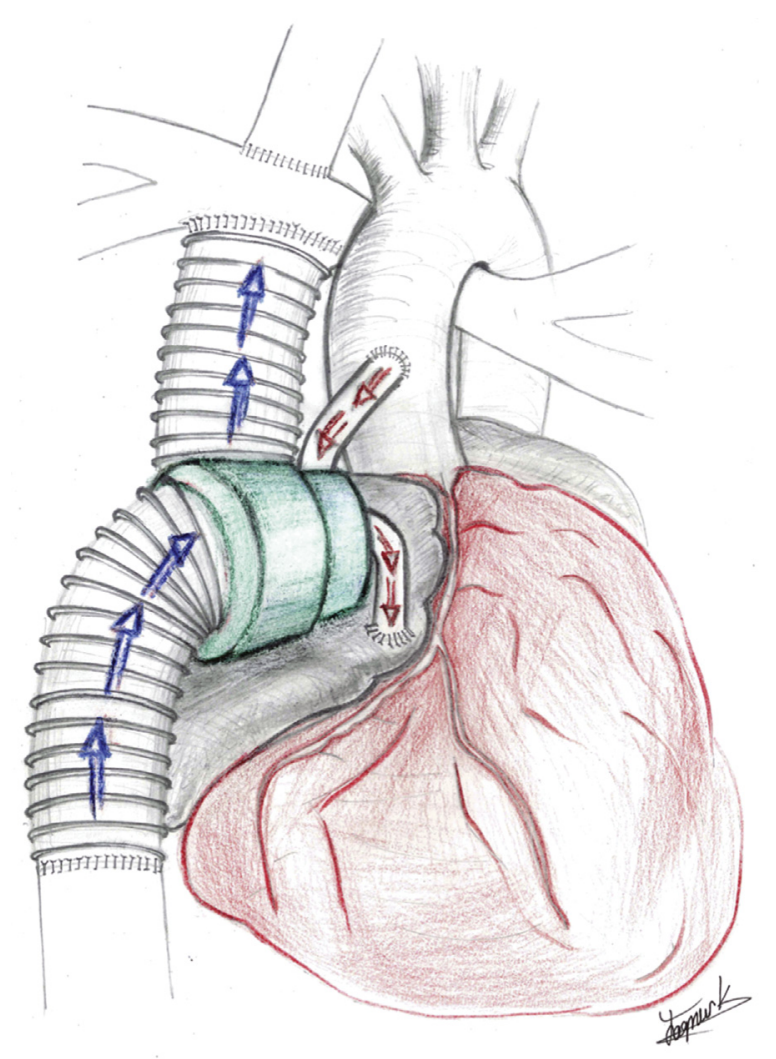

FIGURE 1. Chronic mechanical venous support without external drive power for Fontan patients. An iATVA device connected through a common shaft that steals a minimal amount of aortic blood to drive a blood turbine and transfers this available pumping energy to the venous side where it is most needed. The iATVA device can resolve the Fontan paradox passively by reversing its gradual vascular complications. The main function of the blood turbine-the inlet/outlet of which can be reconstructed from PTFE, is to extract the available energy from the pressure potential difference that exists in typical pediatric shunts, such as the Blalock-Taussig shunt.

\section{In Vitro Mock-Up Flow Loop}

The prototype iATVA systems were evaluated at the bench-top first using a steady turbine inlet flow setup and then using our pulsatile in vitro single-ventricle circuit ${ }^{29,33}$ (Figure E2). Previously, we validated both setups for testing pediatric ventricle assist devices in Fontan circulation and described the experimental approach in detail. ${ }^{29}$ For the instrumentation and setup components for this present study please refer to the Appendix E1 in vitro mock-up flow loop and instrumentation. The iATVA device was located along a bypass line, parallel to the IVC, using Y-connectors, which allowed the instantaneous introduction of the device to the single-ventricle circulation without stopping or dismantling the flow circuit. The total cavopulmonary connection (TCPC) state was first established in accordance with our standard protocol ${ }^{29}$ and any deviations in hemodynamic parameters after the iATVA was introduced were recorded.

\section{RESULTS}

\section{Ideal Device Characteristics}

To our knowledge, this is the first study to examine the turbomachinery design of a blood turbine in cardiovascular device literature. The low aortic steal requirement of the iATVA system results in low turbine specific speeds (nondimensional specific speed $=103$ ) corresponding to mechanically challenging radial impellers, even reaching impulse turbine configuration if higher efficiency is desired. For the venous side a mixed-impeller is found to be optimal to assist the Fontan circulation, with nondimensional specific speed $=1.2$. The rotational speed varies between 800 to 1800 revolutions per minute (rpm), generating a net venous pressure augmentation $(\Delta \mathrm{P})$ of 3 to $12 \mathrm{~mm} \mathrm{Hg}$ through the pump (ie, SVP decrease, pump outlet distal PA pressure increase).

The ideal characteristics of the iATVA system is estimated from turbomachinery theory and summarized in Figure 3. It is observed that for adult as well as pediatric flow requirements the iATVA system can provide sufficient venous pressure ramp at the pump impeller that drives the IVC flow for a conservative power transmission efficiency $(50 \%)$. Even with less than $5 \%$ of aortic steal, up to $5 \mathrm{~mm}$ $\mathrm{Hg}$ venous pressure augmentation is possible. As the power generation chart in Figure 3 (top row) indicates, higher turbine outer diameter and blade trail end angle leads to a higher power generation. To achieve a stable operating point and small turbine size for easy implantation, the prototype design dimensions are located at the relatively flat region resulting in a turbine outer diameter of $38 \mathrm{~mm}$ (see Figure 3, top left). Coupled to this selected turbine operating point, the corresponding venous pump characteristics are summarized in Figure 3 (top right) where an impeller blade height of $10 \mathrm{~mm}$ and pump diameter of $32 \mathrm{~mm}$ was chosen for a blade trail angle of $60^{\circ}$. For an adult Fontan patient having a cardiac output of 5 LPM and high IVC flow split $80 \%$ (4 LPM), pump $\Delta \mathrm{P}$ is approximately $7.8 \mathrm{~mm} \mathrm{Hg}$ for an aortic steal of $10 \%$ at $90 \mathrm{~mm} \mathrm{Hg} \mathrm{systemic} \mathrm{pressure.} \mathrm{For} \mathrm{this} \mathrm{design,} \mathrm{the}$ pediatric flow requirements that have lower CO (3 LPM) and more balanced IVC/SVC flow split, lead to higher $\Delta \mathrm{P}$ values reaching $15 \mathrm{~mm} \mathrm{Hg}$, with an aortic flow steal of $10 \%$ and $90 \mathrm{~mm} \mathrm{Hg}$ systemic pressure (Figure 3).

\section{Steady-State Device Characteristics}

The iATVA prototypes are tested at different steady turbine inflow rates (aortic steal) and the corresponding net venous pressure decrease $(\Delta \mathrm{P})$, delivered to the pump side at IVC is recorded (Figure 4). For prototypes P2 and $\mathrm{P} 3$, a $\Delta \mathrm{P}$ of $5 \mathrm{~mm} \mathrm{Hg}$ is achieved at $1 \mathrm{LPM}$ turbine flow. When the turbine flow is increased slightly to $1.2 \mathrm{LPM}$ pressure increase doubles.

Lower rotational speeds than predicted by the ideal design are observed (see Figure 4). For P1, the delivered pressure head is stabilized after $400 \mathrm{rpm}$ driven by a turbine flow of 0.95 LPM. At a flow rate of $1.3 \mathrm{LPM}$, an impeller speed of $700 \mathrm{rpm}$ is recorded. For P2 and P3, higher impeller speeds are achieved because of the torque increase 

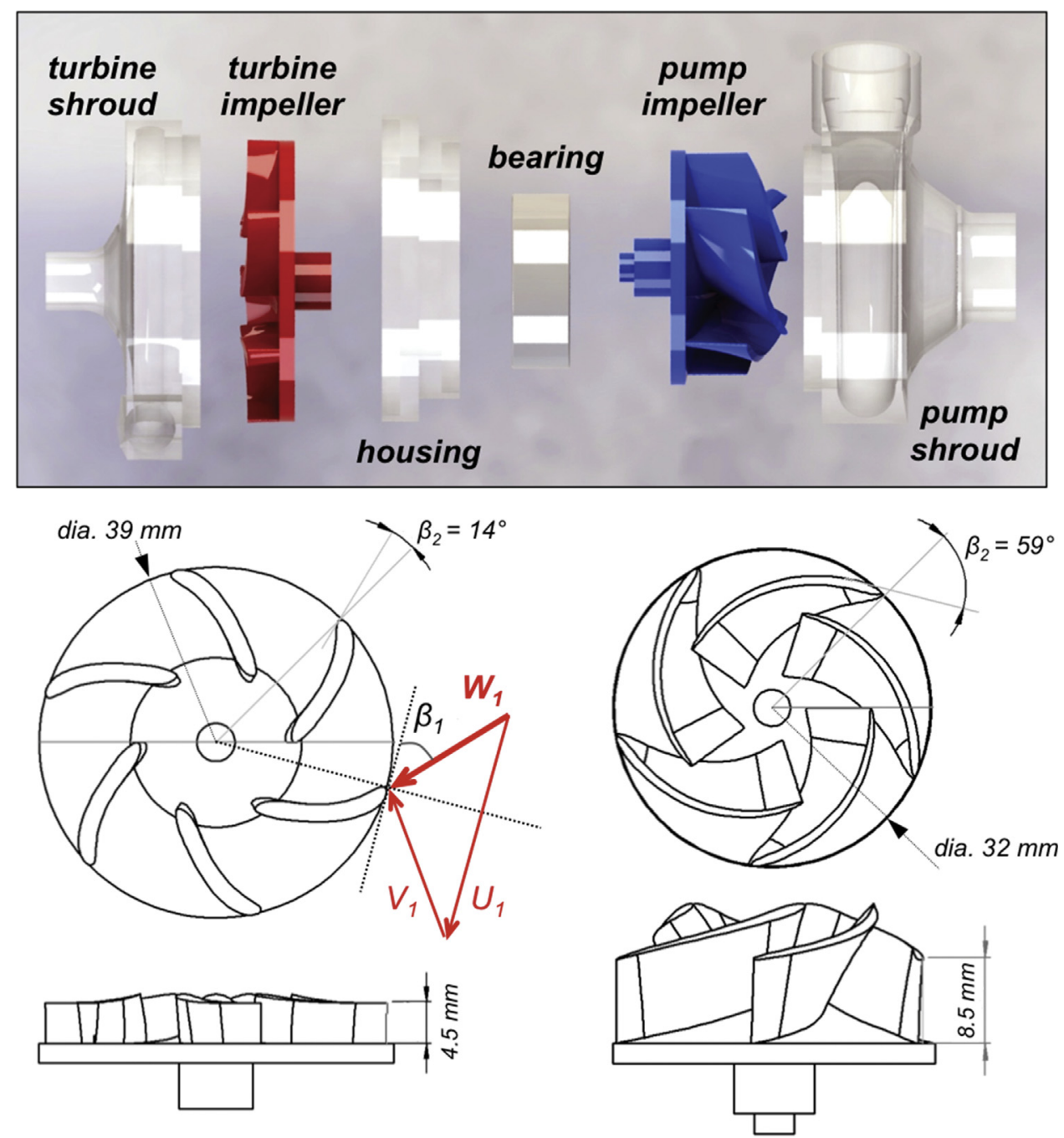

FIGURE 2. Top row: Components and assembly of the iATVA. Bottom row: Basic blade angles and impeller dimensions (in millimeters) for the turbine and pump side. The turbine and pump side of the device is designed to be enclosed in a single chamber. The completed device is made of 5 parts: turbine shroud, turbine impeller, pump shroud, pump impeller, and a connection housing in between, which is attached to both shrouds and carries the single bearing holding both impellers. All attachments are designed to be a tight fit.

provided by a larger volute design. Although P2 and P3 show a similar performance between 0.85 and $1.3 \mathrm{LPM}$ turbine drive flow, the torque increase in P3 design allows for very low aortic flow extraction, reaching 0.6 LPM and providing approximately a $1-\mathrm{mm} \mathrm{Hg}$ venous pressure augmentation.

\section{Pulsatile In Vitro Performance}

In the mock-up circuit, the single-ventricle (TCPC) circulation is first established with 86.1 and $96.2 \mathrm{~mm} \mathrm{Hg}$ mean aortic pressure for pediatric and adult hemodynamics, respectively. The corresponding mean IVC flow is recorded as 2.2 LPM (pediatric) and 3.2 LPM (adult), and the sample waveforms are provided in Figure 5. When iATVA prototype 3 is introduced, turbine impeller rotation is observed immediately. An aortic steal of 1 LPM results in an acute decrease in average systemic pressure levels reaching $59.7 \mathrm{~mm} \mathrm{Hg}$ (80.5 systolic, 46.3 diastolic) and $74.8 \mathrm{~mm} \mathrm{Hg}$ (95.6 systolic, 64.2 diastolic) for pediatric and adult conditions respectively, which are adjusted back to their initial systemic pressure levels. The IVC/SVC flow splits are kept approximately constant and a venous pressure level of $11.4 \mathrm{~mm} \mathrm{Hg}$ (pediatric) and $12.1 \mathrm{~mm} \mathrm{Hg}$ (adult) is recorded through a net pump assist of 2 to $3 \mathrm{~mm}$ $\mathrm{Hg}$ (Figure 5). Sample cardiac-cycle averaged measurements with and without iATVA are provided in Table 1.

The decreased arterial pressure can also be regulated physiologically through increased cardiac output (increased heart rate and stroke volume), which is also tested in our mock-up circuit. As expected, these experiments indicate a better performance where the "main outcome" IVC 

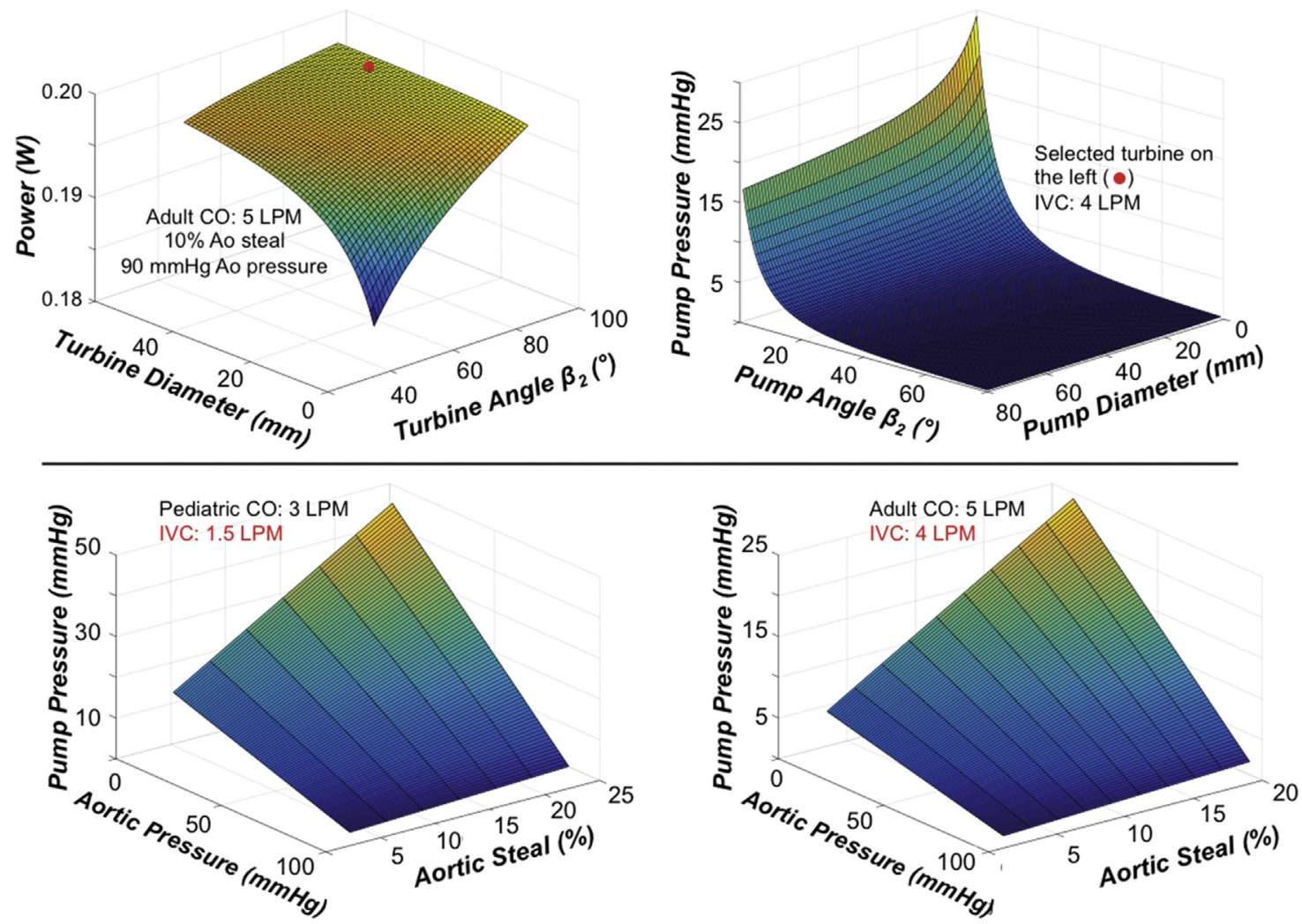

FIGURE 3. Ideal characteristics of the iATVA system estimated from turbomachinery theory. Top row: On the left, available turbine power is plotted as a function of turbine outer diameter and outlet blade angle, for adult total cardiac output $(C O)$ and corresponding inferior vena cava (IVC) flow split ( $80 \%$ ). Note that the turbine power is equal to pump power divided by the total mechanical efficiency $(0.50)$. Selected operating point of the iATVA prototype is shown as a red dot. On the right, for this operating point (shown on left) the pump side performance is plotted as a function of outlet blade angle and pump outer diameter. Characteristics for the pediatric flow conditions are similar. Bottom row: Possible venous pressure decrease ranges for the pump impeller as a function of the turbine pressure decrease (aortic minus turbine outlet) and aortic steal percent. Pediatric and adult flow conditions are shown on the left and right, respectively. $L P M$, Liters per minute.

pressure can be reduced by up to $8 \mathrm{~mm} \mathrm{Hg}$, compared with the TCPC state without venous assist (see Table E3). While regulating the $\mathrm{CO}$, a slight increase in venous pressure due to intravascular volume increase would not alter the level of pressure decrease provided by the iATVA system at the venous side.

Similarly, iATVA devices (versions P2 and P3) are tested at different turbine flow rates and the corresponding mean hemodynamic values are reported in Figure E3. Higher venous pressure decrease at the IVC (pump inlet) resulted due to increased aortic steal, for adult as well as pediatric conditions. However, a positive venous assist is also possible up to a turbine flow limit of approximately 0.9 LPM (18\% aortic steal in adult) for the current prototype designs. For low aortic steal conditions, the flow leakage from the turbine side to the pump side becomes significant reaching 0.2 to $0.4 \mathrm{LPM}$, which degrades the turbine efficiency abruptly. Prototype P3 with additional turbine blades results in the highest $\Delta \mathrm{P}$ at the design operating points; $2 \mathrm{~mm} \mathrm{Hg}$ at $0.98 \mathrm{LPM}$ (pediatric) and $2 \mathrm{~mm} \mathrm{Hg}$ at 1.1 LPM (adult). This performance is equivalent to the
Fontan pumps reported in the literature (Table E1). In Figure 6, all 3 iATVA prototypes are compared, which show improved performance as the design is evolved. As such, the impeller speed is shown to be an important index of system performance. Further results are provided in the section "Effect of Rotational Speed" in Appendix E1.

\section{DISCUSSION}

Delivery of the external power required to drive the mechanical assist devices is a formidable bioengineering challenge. Infections caused by the external power driveline are a major device-related complication of totally implanted mechanical assist devices. ${ }^{34}$ As such, for pediatric extracorporeal systems like the Berlin heart EXCOR (Berlin Heart GmbH, Berlin, Germany), similar infections are caused by the inlet/outlet tubes. ${ }^{35}$ It is significant to note that approximately $35 \%$ of pediatric ventricle support cases have resulted an infection-related complication as reported in PediMACS. ${ }^{36}$ Although a number of intraoperative remedies to reduce infection are proposed, ${ }^{37}$ the ultimate solution is to power ventricular assist devices 


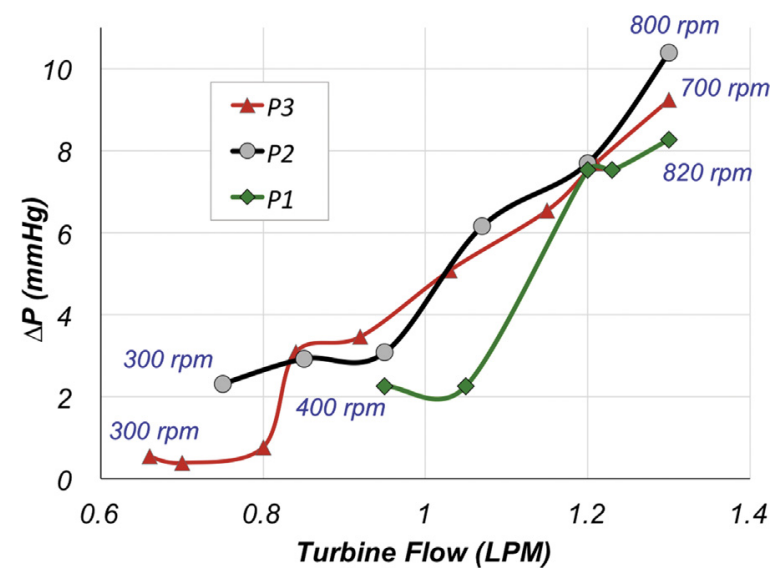

FIGURE 4. For the 3 iATVA prototypes $(P 1, P 2$, and $P 3)$ corresponding venous pressure increase subject to a steady aortic turbine flow rate is plotted. Rotational speeds are measured at selected operating points labeled in blue. Positive pump pressures are recorded for all operating points. The $95 \%$ confidence interval for flow and pressure measurements are 0.014 liters per minute $(L P M)$ and $0.29 \mathrm{~mm} \mathrm{Hg}$, respectively. Turbine pressure decrease varies 70 to $100 \mathrm{~mm} \mathrm{Hg}$ for 1.0 to $1.3 \mathrm{LPM}$ blood turbine operating flow rates. $\Delta P$, Net venous pressure augmentation provided by the pump impeller.

wirelessly through the transcutaneous energy transfer. ${ }^{38}$ The major challenges of this approach include thermal tissue damage and unintended electromagnetic neural stimulation. $^{39}$ Furthermore, poor power transmission efficiency has the potential to limit the hydrodynamic performance of ventricular assist. Cardiac assist systems that harvest the skeletal muscle power ${ }^{40-42}$ to drive an IVC cuff, ${ }^{43,44}$ atrial cardiomyoplasty, ${ }^{45}$ or tissueengineered beating TCPC conduits, ${ }^{46}$ can eliminate the need for external power. However, these systems also have poor power transmission efficiency and for any meaningful IVC support, require pacing systems and valves to synchronize with the venous pulsatility. ${ }^{47,48}$ The proposed iATVA configuration addresses the need for external drive power through a novel alternative concept that particularly suits single-ventricle patients because of its passively controlled characteristics.

On the basis of our current experiments with iATVA, for a typical Fontan circulation, it would be unlikely to demand further turbine power to drive the venous pump. Even if higher drive power is required, the aortic flow extraction budget of iATVA can be increased beyond $10 \%$ to $20 \%$, on the basis of the current experience with the first stage systemic-to-pulmonary shuts that are routinely used in staged single-ventricle palliation. Depending on the disease template, aortic steal through these shunts can reach up to $50 \%$ of the CO.$^{49,50}$ Likewise, when a Fontan fenestration is used, up to $30 \%$ preload increases are common. Furthermore, for shunt as well as fenestration systems the available hydrodynamic energy is expanded without doing any useful work and with oxygen desaturation. Systemic desaturation at the venous side, as well as the uncontrolled shunt pressure/flow expansion, increases the risk of paradoxical emboli and stroke. In contrast, the aortic steal of IATVA is delivered to the atrium without influencing the oxygen saturation levels and thus reduces the risk of stroke. Furthermore, a more moderate, controlled expansion is achieved through the turbine compared with a traditional shunt. Although long-term aortic steal to drive the turbine can be considered as an additional burden for the single ventricle, there are cases in the literature in which pulmonary flow is very well tolerated spontaneously with age until 60 to 70 years, without any surgery. ${ }^{51}$

Considering the energy harvest possibility from the systemic-pulmonary shunts, it is also important to discuss the new arterial-to-venous pathway intended to augment the SVC flow at the Glenn stage. ${ }^{31,52}$ In this system, high-pressure aortic flow expands to the venous pressure levels but without doing any turbine work, limiting its performance significantly. Compared with the iATVA device, the assisted-Glenn shunt configuration also steals a similar amount of aortic blood reaching $15 \%$ to $28 \%$. Therefore, the iATVA system can be considered as a novel extension of pediatric systemic shunts by extracting useful energy from the aortic and venous pressure difference, with no oxygen desaturation or energy loss. This available energy is relocated to the venous side, a location where extra pumping energy is most needed to drive any type of venous assist device (centrifugal or axial) in the singleventricle circulation passively.

This in vitro study proves the feasibility of the iATVA configuration but major design improvements are possible for future prototypes. It is anticipated that the final version of implanted iATVA devices in animals or humans will be significantly different. For example, a double-inlet configuration collecting IVC as well as SVC flows into the pump through a Y-graft, and then delivers the venous blood to both PAs via a specially designed volute. This configuration would improve performance and result in an optimal default TCPC pathway in the event of turbine power failure (see Figure E1, Configuration C3, resembling an augmented 4-way $\mathrm{TCPC}^{53}$ ), because the present calculations indicate that the theoretical available turbine head has the potential to support the entire venous return. Whereas for configuration $\mathrm{C} 1$ and $\mathrm{C} 3$, there is a risk of stroke as in the traditional left ventricle assist devices; this risk is mitigated in other configurations $\mathrm{C} 2$ and $\mathrm{C} 4$, in which the blood turbine bears almost the same risk as a systemic-to-pulmonary shunt. Using this alternative circuit configuration, given the passive nature of the iATVA system, instead of the traditional extracardiac TCPC, an "assisted-TCPC" can be implanted immediately as the third stage completion. Our experiments indicate that the 


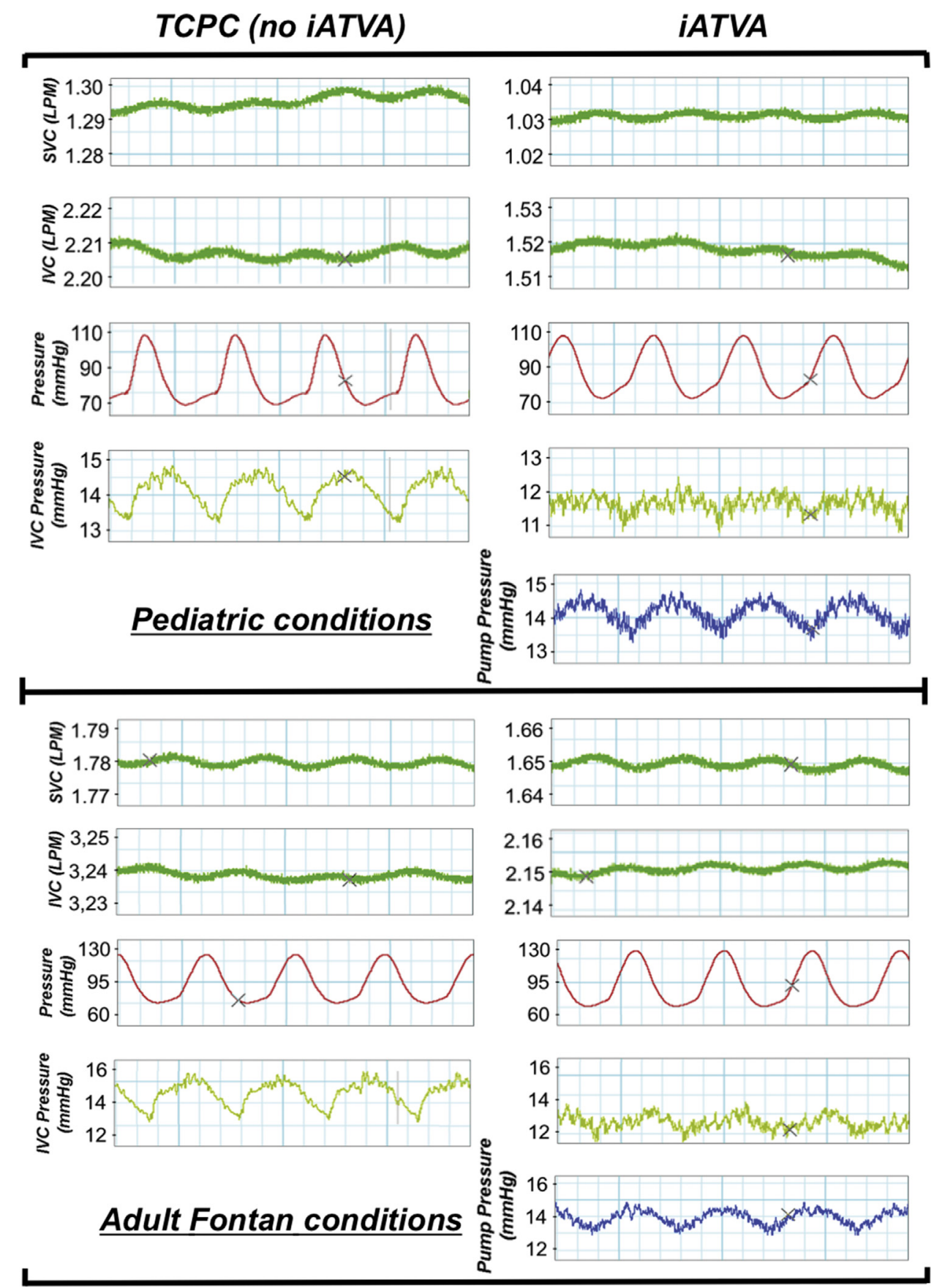

FIGURE 5. Sample hemodynamic waveforms established for the single-ventricle (TCPC) state, with iATVA (right column) and without iATVA (left column), in the mock-up circuit. "Pump pressure" is measured at the outlet of the pump corresponding to the pulmonary artery pressure. Pediatric and adult Fontan hemodynamic conditions correspond to 3.5 and 5 liters per minute ( $L P M)$ of total cardiac output, respectively, and satisfy the corresponding SVC/ IVC flow splits as stated in the text. Measurements correspond to iATVA prototype 3, which is connected to the system with a $\mathrm{Y}$ connector in between the IVC outlet and TCPC inlet. The pump is switched on by removing the clamps on the turbine inlet and pump inlet. Average hemodynamic values and waveforms established for the single-ventricle (TCPC) state (without iATVA) in the mock-up circuit are provided in Table 1. TCPC, Total cavopulmonary connection; iATVA, integrated aortic-turbine venous-assist; SVC/IVC, superior vena cava/inferior vena cava.

iATVA system for Fontan physiology is a "turbine performance-limited" system and turbine-operating conditions pose a challenging turbomachinery problem. In particular, a more detailed volute design and volute-impeller interaction study must be conducted for assuring a higher efficiency. Likewise, the iATVA system is the first blood turbine proposed in the literature to our knowledge, and its blood damage and platelet activation characteristics 
TABLE 1. Sample hemodynamic measurements obtained during the pulsatile mock-up single-ventricle flow loop experiments

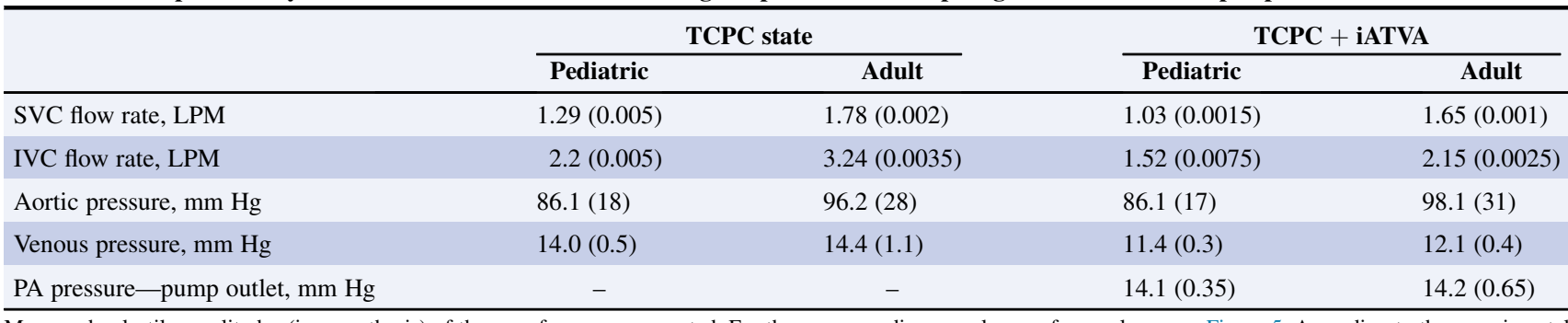

Mean and pulsatile amplitudes (in parenthesis) of the waveforms are presented. For the corresponding sample waveforms please see Figure 5. According to the experimental protocol, first the TCPC state is established and then the iATVA device is introduced leading the TCPC + iATVA hemodynamics. Values are provided for prototype 3. $T C P C$, Total cavopulmonary connection; $i A T V A$, integrated aortic-turbine venous-assist; $S V C$, superior vena cava; $L P M$, liters per minute; $I V C$, inferior vena cava; $P A$, pulmonary artery.

pose an intriguing research problem, which need to be compared with the traditional pump side assist. It is expected that the thrombogenicity of the turbine side would be significantly different than the pump side. Whereas the iATVA system maintains significantly lower rotational speeds than the existing percutaneous ventricular assist devices, it might still require a higher dose of anticoagulants because it incorporates the venous as well as aortic systems. Steady-flow tests are generally shown to be parallel with the theoretical design predictions, but a detailed design focusing on frictional losses and turbine-to-pump leakage becomes evident for low aortic flow steal values reaching 0.5 LPM. Therefore, a new prototype that uses magnetic coupling (with total separation of systemic and venous blood) and higher-quality ultra-low friction ceramic bearings was developed in our laboratory. The initial in vitro tests of this prototype has produced encouraging results, which we plan to publish in the future.

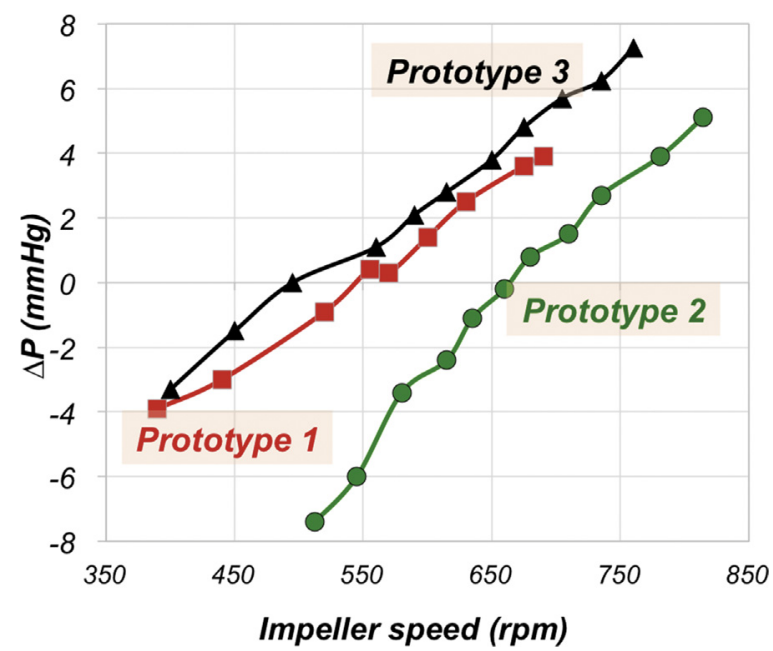

FIGURE 6. Performance comparison of the 3 iATVA prototypes in pulsatile hemodynamic conditions generated in the single-ventricle mock-up flow loop. Results correspond to the adult Fontan hemodynamics at 5 LPM total cardiac output. Negative $\Delta \mathrm{P}$ values are due to bearing leakage and insufficient aortic steal. Error bars are omitted for clarity because $\Delta \mathrm{P}$ values between the pumps are statistically significant. $\Delta P$, Net venous pressure augmentation provided by the pump impeller.
The flat characteristic response of the iATVA device (Figure 3) and its passive nature make it advantageous during off-design operation, compared with the traditional mechanical assist devices. For example, physical exercise would result in a positive effect on iATVA performance because of the sixfold increase in $\mathrm{CO}$ and a weaker heart rate and systemic pressure increase. One major failure mode is anticipated to be the turbine flow pathway blockage due to low aortic steal that can result in clotting. Such patients would require high-dose anticoagulation therapy. This failure mode was tested by clamping the turbine inflow and simultaneously fixing the shaft rotation in which the pump impeller did not cause a major obstruction to the freely-flowing IVC blood, whereby the hemodynamic parameters returned back to their TCPC state. For iATVA prototype 3 , the pump-side pressure decrease for a freely rotating impeller is less than $3 \mathrm{~mm} \mathrm{Hg}$ (with no turbine drive power), which increases to approximately $5 \mathrm{~mm} \mathrm{Hg}$ when the impeller rotation is restricted fully, including the TCPC pathway flow resistance (see Table E3 for these mock-up system experiments). To meet the failsafe constraint of no obstruction in the event of device dysfunction, the pump-side free-flow (TCPC state) pressure decrease of the iATVA system can be reduced further through the origami-inspired retractable or foldable impellers. ${ }^{54,55}$ In some patients, an acute Fontan failure is also anticipated after iATVA device implantation that can be recovered through an emergency mechanical assist (atrio-aortic) device application.

Future research will determine whether the proposed concept will enable breakthrough postoperative management strategies for single-ventricle patients to control high SVP and also challenge the conventional stagedFontan timing. In particular, the long-term use of the iATVA system to complement and support single-ventricle performance as a prophylactic strategy in asymptomatic Fontan patients to decrease the workload on the single ventricle and eliminate the venous remodeling, is also theoretically possible to extend the life of the ventricle and ultimately the patient. Thus, optimal iATVA timing does not have to correspond to the terminal stage of Fontan failure where 


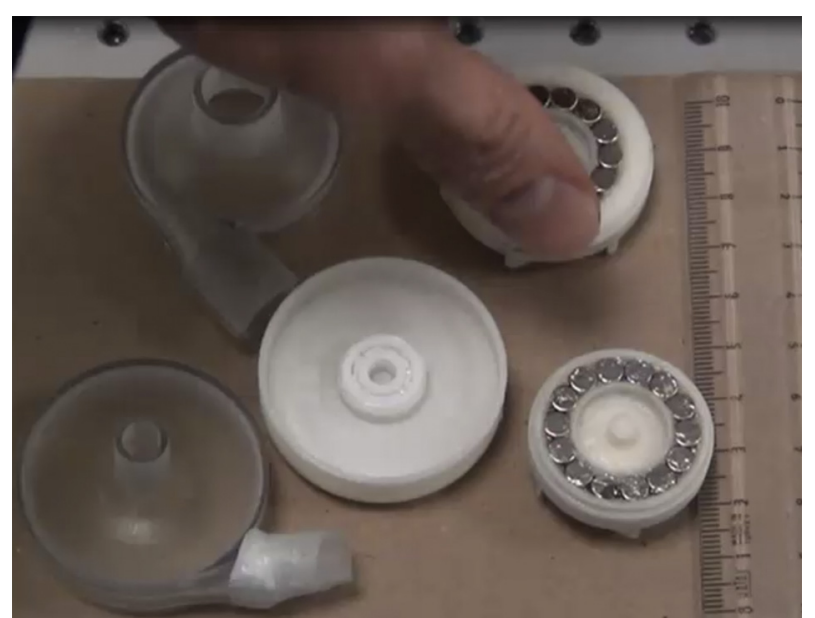

VIDEO 1. Assembly process of a magnetically coupled integrated aorticturbine venous assist device (iATVA) with ceramic bearings. The iATVA prototype supporting a single-ventricle circulation, in vitro demonstrated through an instrumented mock-up flow loop. Video available at: http:// www.jtcvsonline.org/article/S0022-5223(18)30717-7/fulltext.

the pulmonary vascular resistance is very high and $\mathrm{CO}$ needed to drive the turbine is low. Instead iATVA device implantation can be considered as soon as an elevated SVP is diagnosed, together with the initiation of protein-losing enteropathy and when plastic bronchitis symptoms are observed. Because of space problems, the present device size would fit children larger than $20 \mathrm{~kg}$, by extending it approximately $2 \mathrm{~cm}$ over the TCPA graft (a total of $4 \mathrm{~cm}$ ) toward the right pleura. Smaller-size devices are also theoretically feasible as presented in Figure E6.

Finally, we have shown that all components of the iATVA system can be manufactured through rapid prototyping, offering an inexpensive device alternative that has the potential to be customized for the individual patient and disease states and address the challenge of large patient-to-patient variation. In our experiments, we observe that a moderate level of venous pulsatility is generated at the PAs because of the systemic turbine impeller that fluctuates with the cardiac cycle. Future designs can specifically seek to improve pulsatile performance through stiffer outlets, which would be beneficial for healthy PA growth and remodeling.

\section{CONCLUSIONS}

This research study proposes a novel mechanical assist device for Fontan patients that does not require an external drive power. Turbomachinery theory and bench-top single-ventricle flow circuit data from evolving prototypes support the feasibility of this concept. Founded on the clinical experience with systemic shunts, the iATVA system requires minimal aortic steal, and uses this energy to generate the needed venous pressure reduction. Present prototypes require further improvements in leakage control, off-design operation (eg, high pulmonary vascular resistance), turbine drainage, and pulsatility. Intriguing research opportunities for the cardiovascular device community are identified by this study, including the thrombogenicity budget of the turbine section compared with a traditional "pump-only" percutaneous ventricular assist devices. Thus, the exciting iATVA system has the potential to passively reverse the detrimental effects of single-ventricle circulation and is expected to lead to further innovations in staged palliation of congenital heart disease management. The timing of iATVA system implantation is clinically precarious and strategies that optimize single-ventricle hemodynamics would likely reduce morbidity as well as mortality. Because the third-stage Fontan completion is typically performed at approximately 2 to 3 years of age, the available thoracic volume for device insertion might still be inadequate, even considering the potential benefits of the iATVA system. Therefore, clinicians can consider a new fourth stage for iATVA implantation to realize its optimal use.

Many single-ventricle patients who have been surgically palliated with a modified Fontan operation eventually develop a low $\mathrm{CO}$ syndrome associated with systemic venous congestion resistant to medical management. Problematic atriopulmonary connection templates and pathway stenosis can otherwise be treated via surgical or catheterized TCPC conversion, providing approximately 1 to $3 \mathrm{~mm} \mathrm{Hg}$ improvements in $\mathrm{SVP}^{56}$ which is equivalent to a similar benefit that would be provided by a typical Fontan venous assist device, similar to the iATVA pump. There is also a small subgroup of "real" failed Fontan patients with high pulmonary vascular resistance, for whom the only treatment option is cardiac transplantation. There is also the possibility that the iATVA system can heal this small patient group in significant time before the terminal failed-state is reached, which requires further investigation.

\section{Conflict of Interest Statement}

Authors have nothing to disclose with regard to commercial support.

\section{References}

1. Fontan F, Baudet E. Surgical repair of tricuspid atresia. Thorax. 1971;26:240-8.

2. Fontan F, Deville C, Quaegebeur J, Ottenkamp J, Sourdille N, Choussat A, et al. Repair of tricuspid atresia in 100 patients. J Thorac Cardiovasc Surg. 1983;85: 647-60.

3. Kreutzer G, Galíndez E, Bono H, De Palma C, Laura JP. An operation for the correction of tricuspid atresia. J Thorac Cardiovasc Surg. 1973;66:613-21.

4. de Leval M. The Fontan circulation: what have we learned? What to expect? Pediatr Cardiol. 1988;19:316-20.

5. de Leval M. The Fontan circulation: a challenge to William Harvey? Nat Clin Pract Cardiovasc Med. 2005;2:202-8.

6. Marino B. Outcomes after the Fontan procedure. Curr Opin Pediatr. 2002;14: 620-6.

7. Kavarana MN, Pagni S, Recto MR, Sobczyk WL, Yeh T Jr, Mitchell M, et al. Seven-year clinical experience with the extracardiac pedicled pericardial Fontan operation. Ann Thorac Surg. 2005;80:37-43.

8. Cilliers A, Gewillig M, Cilliers A, Gewillig M. Fontan procedure for univentricular hearts: have changes in design improved outcome? Cardiovasc J S Afr. 2002; 13:111-6. 
9. Kim SJ, Kim WH, Lim HG, Lee CH, Lee JY. Improving results of the Fontan procedure in patients with heterotaxy syndrome. Ann Thorac Surg. 2006;82:1245-51.

10. Mair DD, Puga FJ, Danielson GK. The Fontan procedure for tricuspid atresia: early and late results of a 25-year experience with 216 patients. J Am Coll Cardiol. 2001;37:933-9.

11. Mitchell ME, Ittenbach RF, Gaynor JW, Wernovsky G, Nicolson S, Spray T, et al. Intermediate outcomes after the Fontan procedure in the current era. J Thorac Cardiovasc Surg. 2006;131:172-80.

12. Kelly J, Mack G, Fahey J. Diminished venous vascular capacitance in patients with univentricular hearts after the Fontan operation. Am J Cardiol. 1995;76:158-63.

13. Menon S, Chennapragada M, Ugaki S, Sholler GF, Ayer J, Winlaw DS. The lymphatic circulation in adaptations to the Fontan circulation. Pediatr Cardiol. 2017:38:886-92.

14. Rychik J. The relentless effects of the Fontan paradox. Semin Thorac Cardiovasc Surg Pediatr Card Surg Annu. 2016;19:37-43.

15. Albal P, Menon P, Kowalski W, Undar A, Turkoz R, Pekkan K. Novel fenestration designs for controlled venous flow shunting in failing Fontans with systemic hypertension. Artif Organs. 2013;37:66-75.

16. Woods RK, Ghanayem NS, Mitchell ME, Kindel S, Niebler RA. Mechanical circulatory support of the Fontan patient. Semin Thorac Cardiovasc Surg Pediatr Card Surg Annu. 2017;20:20-7.

17. Chopski SG, Moskowitz WB, Stevens RM, Throckmorton AL. Mechanical circulatory support devices for pediatric patients with congenital heart disease. Artif Organs. 2017;41:E1-14.

18. Rodefeld MD, Boyd JH, Myers CD, LaLone BJ, Bezruczko AJ, Potter AW, et al. Cavopulmonary assist: circulatory support for the univentricular Fontan circulation. Ann Thorac Surg. 2003;76:1911-6; discussion: 1916.

19. Myers CD, Boyd JH, Presson RG Jr, Vijay P, Coats AC, Brown JW, et al. Neonatal cavopulmonary assist: pulsatile versus steady-flow pulmonary perfusion. Ann Thorac Surg. 2006;81:257-63.

20. Myers CD, Mattix K, Presson RG Jr, Vijay P, Maynes D, Litwak KN, et al. Twenty-four hour cardiopulmonary stability in a model of assisted newborn Fontan circulation. Ann Thorac Surg. 2006;81:264-70; discussion 270-1.

21. Russo P, Wheeler A, Russo J, Tobias JD. Use of a ventricular assist device as a bridge to transplantation in a patient with single ventricle physiology and total cavopulmonary anastomosis. Paediatr Anaesth. 2008;18:320-4.

22. Calvaruso DF, Ocello S, Salviato N, Guardì D, Petruccelli DF, Rubino A, et al. Implantation of a Berlin heart as single ventricle by-pass on Fontan circulation in univentricular heart failure. ASAIO J. 2007;53:e1-2.

23. Chu MW, Sharma K, Tchervenkov CI, Jutras LF, Lavoie J, Shemie SD, et al. Berlin heart ventricular assist device in a child with hypoplastic left heart syndrome. Ann Thorac Surg. 2007;83:1179-81.

24. Jacobs JP, Quintessenza JA, Chai PJ, Lindberg HL, Asante-Korang A, McCormack J, et al. Rescue cardiac transplantation for failing staged palliation in patients with hypoplastic left heart syndrome. Cardiol Young. 2006;16:556-62.

25. Nathan M, Baird C, Fynn-Thompson F, Almond C, Thiagarajan R, Laussen P, et al. Successful implantation of a Berlin heart biventricular assist device in a failing single ventricle. J Thorac Cardiovasc Surg. 2006;131:1407-8.

26. Newcomb AE, Negri JC, Brizard CP, d'Udekem Y. Successful left ventricular assist device bridge to transplantation after failure of a fontan revision. $J$ Heart Lung Transplant. 2006;25:365-7.

27. Rodefeld MD, Frankel SH, Giridharan GA. Cavopulmonary assist: (em)powering the univentricular fontan circulation. Semin Thorac Cardiovasc Surg Pediatr Card Surg Annu. 2011;14:45-54.

28. Pekkan K, Frakes D, De Zelicourt D, Lucas CW, Parks WJ, Yoganathan AP. Coupling pediatric ventricle assist devices to the Fontan circulation: simulations with a lumped-parameter model. ASAIO J. 2005;51:618-28.

29. Dur O, Lara M, Arnold D, Vandenberghe S, Keller BB, DeGroff C, et al. Pulsatile in vitro simulation of the pediatric univentricular circulation for evaluation of cardiopulmonary assist scenarios. Artif Organs. 2009;33:967-76.

30. Kocyildirim E, Dur O, Soran O, Tuzun E, Miller MW, Housler GJ, et al. Pulsatile venous waveform quality in Fontan circulation-clinical implications, venous assists options and the future. Anadolu Kardiyol Derg. 2012;12:420-6.

31. DeCampli WM. The steam locomotive makes a comeback: a new solution to staged single-ventricle palliation? J Thorac Cardiovasc Surg. 2015;149:706-7.

32. Rodefeld MD, Coats B, Fisher T, Giridharan GA, Chen J, Brown JW, et al. Cavopulmonary assist for the univentricular Fontan circulation: von Karman viscous impeller pump. J Thorac Cardiovasc Surg. 2010;140:529-36.

33. Dur O, Yoshida M, Manor P, Mayfield A, Wearden PD, Morell VO, et al. In vitro evaluation of right ventricular outflow tract reconstruction with bicuspid valved polytetrafluoroethylene conduit. Artif Organs. 2010;34:1010-6.
34. Holman WL, Rayburn BK, McGiffin DC, Foley BA, Benza RL, Bourge RC, et al Infection in ventricular assist devices: prevention and treatment. Ann Thorac Surg. 2003;75:S48-57.

35. Zafar F, Jefferies JL, Tjossem CJ, Bryant R III, Jaquiss RD, Wearden PD, et al Biventricular Berlin heart EXCOR pediatric use across the United States. Ann Thorac Surg. 2015;99:1328-34.

36. Blume ED, Rosenthal DN, Rossano JW, Baldwin JT, Eghtesady P, Morales DL, et al. Outcomes of children implanted with ventricular assist devices in the United States: first analysis of the pediatric interagency registry for mechanical circulatory support (PediMACS). J Heart Lung Transplant. 2016;35:578-84.

37. Entwistle J. Intraoperative positioning to prevent driveline insulation from acting as a conduit for left ventricular assist device pocket infection. J Thorac Cardiovasc Surg. 2014;148:2437.

38. Wang JX, Smith JR, Bonde P. Energy transmission and power sources for mechanical circulatory support devices to achieve total implantability. Ann Thorac Surg. 2014;97:1467-74.

39. Lucke L, Bluvshtein V. Safety considerations for wireless delivery of continuous power to implanted medical devices. Conf Proc IEEE Eng Med Biol Soc. 2014 2014:286-9.

40. Trumble D, Magovern J. Muscle-powered mechanical blood pumps. Science. 2002;296:1967.

41. Trumble D, Magovern J. Capturing in situ skeletal muscle power for circulatory support: a new approach to device design. ASAIO J. 2003;49:480-5.

42. Takahashi M, Misaki T, Watanabe G, Ohtake H, Tsunezuka Y, Wada M, et al. Efficacy of a skeletal muscle-powered dynamic patch: part 1. left ventricular assistance. Ann Thorac Surg. 1995;59:305-12.

43. Valdovinos J, Shkolyar E, Carman GP, Levi DS. In vitro evaluation of an external compression device for fontan mechanical assistance. Artif Organs. 2014;38 199-207.

44. Yamada A, Shiraishi Y, Miura H, Hashem HM, Tsuboko Y, Yamagishi M, et al Development of a thermodynamic control system for the Fontan circulation pulsation device using shape memory alloy fibers. J Artif Organs. 2015;18:199-205.

45. Voss B, Sack FU, Saggau W, Hagl S, Lange R. Atrial cardiomyoplasty in a Fontan circulation. Eur J Cardiothorac Surg. 2002;21:780-6.

46. Biermann D, Eder A, Arndt F, Seoudy H, Reichenspurner H, Mir T, et al. Towards a tissue-engineered contractile Fontan-conduit: the fate of cardiac myocytes in the subpulmonary circulation. PLoS One. 2016;11:e0166963.

47. Santhanakrishnan A, Maher KO, Tang E, Khiabani RH, Johnson J, Yoganathan AP. Hemodynamic effects of implanting a unidirectional valve in the inferior vena cava of the Fontan circulation pathway: an in vitro investigation. Am J Physiol Heart Circ Physiol. 2013;305:H1538-47.

48. Dur O, DeGroff CG, Keller BB, Pekkan K. Optimization of inflow waveform phase-difference for minimized total cavopulmonary power loss. J Biomech Eng. 2010;132:031012.

49. Piskin S, Altin HF, Yildiz O, Bakir I, Pekkan K. Hemodynamics of patientspecific aorta-pulmonary shunt configurations. J Biomech. 2017;50:166-71.

50. Piskin S, Unal G, Arnaz A, Sarioglu T, Pekkan K. Tetralogy of Fallot surgical repair: shunt configurations, ductus arteriosus and the circle of Willis. Cardiovasc Eng Technol. 2017;8:107-19.

51. Gesuete V, Fabi M, Bonvicini MA. 74-year-old unoperated univentricular heart: the oldest reported survival. Cardiol Young. 2016;26:805-7.

52. Esmaily-Moghadam M, Hsia TY, Marsden AL. The assisted bidirectional Glenn: a novel surgical approach for first-stage single-ventricle heart palliation. J Thorac Cardiovasc Surg. 2015;149:699-705.

53. Giridharan GA, Koenig SC, Kennington J, Sobieski MA, Chen J, Frankel SH, et al. Performance evaluation of a pediatric viscous impeller pump for Fontan cavopulmonary assist. J Thorac Cardiovasc Surg. 2013;145:249-57.

54. Rodefeld MD, Steven H, inventors; Indiana University Research and Technology Corporation, assignee. Active or passive assistance in the circulatory system. US patent 8449443. May 28, 2013.

55. Throckmorton AL, Ballman KK, Myers CD, Frankel SH, Brown JW Rodefeld MD. Performance of a 3-bladed propeller pump to provide cavopulmonary assist in the failing Fontan circulation. Ann Thorac Surg. 2008;86:1343-7.

56. Hong H, Dur O, Zhang H, Zhu Z, Pekkan K, Liu J. Fontan conversion templates: patient-specific hemodynamic performance of the lateral tunnel versus the intraatrial conduit with fenestration. Pediatr Cardiol. 2013;34:1447-54.

Key Words: pediatric ventricle assist device, venous hemodynamics, congenital heart disease, single-ventricle physiology, hemodynamics, mock-up circulation tests, Fontan 


\section{APPENDIX E1. SUPPLEMENTARY METHODOLOGY \\ Turbomachinery Calculations}

The turbine and pump impeller shapes are determined on the basis of the corresponding specific speeds, $N_{S}{ }^{37}$ :

$$
N_{s}=\frac{N \sqrt{Q}}{H^{3 / 4}}
$$

where $Q$ is flow rate (liters per second), and $H$ is the hydrodynamic head for the turbine/venous pump (m).

The rotational speed $N(\mathrm{rpm})$ is the same for the turbine as well as the pump impeller because they are connected with the same shaft, which is iterated from the respective coupled hydrodynamic impeller designs of the turbine and the pump side. First, the turbine side is designed with an aortic steal of $<0.5 \mathrm{LPM}$ and the available hydrodynamic rotational torque is used in the pump side design. A conservative transmission mechanical efficiency $\left(\eta_{e}\right)$ of $70 \%$ is presumed for each side of the turbine-pump couple. ${ }^{\mathrm{E} 1, \mathrm{E} 2}$ For the placement of the turbine drainage outlet, 3 alternative locations are considered: common atrium, proximally ligated axillary artery, and distal pulmonary artery, each having different available hydrodynamic drive power (see Figure E1). In this research report, the turbine is located between the aorta and the common atrium (as shown in Figure 1 and Figure E1, Configuration 1), where the maximum available pressure head $\left(\Delta P_{\text {turbine }}\right)$ between the aortic inlet and turbine outlet is approximately $90 \mathrm{~mm}$ $\mathrm{Hg}$. All experiments and parametric design calculations are performed for this turbine inlet/outlet arrangement.

For the turbine inlet velocity triangle (see Figure 2), the impeller velocity $U$ is obtained from:

$$
\rho \cdot U^{2}-\rho \cdot \operatorname{Cot} \beta \cdot V_{r} \cdot U-\Delta P_{\text {turbine }}=0
$$

In this equation $\rho$ is the density of blood, $\beta$ is the blade angle, and blood velocity is decomposed into its radial and tangential components, $V_{r}$ and $V_{\theta}=\Delta P_{\text {turbine }} / \rho U$, respectively. Corresponding rotational speed and turbine torque $T$ are calculated from:

$$
N=2 \cdot \frac{U}{D_{\text {impeller }}} \quad T=\rho Q_{\text {turbine }}\left(r \cdot V_{\theta}\right)
$$

Transferring the rotational speed and available torque to the pump side leads to venous pressure increase for the required venous flow $Q_{\text {pump }}$ :

$$
\Delta P_{\text {pump }}=\eta_{e} N \cdot T / Q_{\text {pump }}
$$

For both impellers, a circular cross-section, spiral singlevolute design, having a volute width equal to the impeller width, is adopted because of their low capacity and low specific speeds. ${ }^{38,39}$ A sharp volute tongue angle, having a more circular circumference around the impeller is used to reduce the local radial forces. Using this procedure, the detailed hydrodynamic designs and impeller surface layouts of 3 iATVA prototypes are generated using NX software (NX 10.0; Siemens Product Lifecycle Management Software Inc, Plano, Tex); the basic parameters are summarized in Table E2.

\section{In Vitro Mock-up Flow Loop and Instrumentation}

Briefly, the single-ventricle flow circuit consists of a 12.62-mm inner diameter glass TCPC connection attached to 4 custom-made compliance chambers (IVC, SVC, right and left pulmonary veins); see Figure E2. A 1-diameter offset TCPC replica is used to reduce the adverse effects of colliding caval flows. In this current study, improved single-ventricle waveforms are realized through the computer-controlled Vivitro pump (Vivitro Labs, Victoria, British Columbia, Canada). Turbine rotational speed (Laser Tachometer-Sinometer DT-2234C; Sanpo Instrument Co Ltd, Guangdong, China), pulsatile flow rates (Transonic PXL-10, PXL-12, Ithaca, NY), and pressure measurements (Utah Medical Products Inc, County Westmeath, Ireland) are recorded using the Lab-chart data acquisition unit (AD Instruments, Colorado Springs, Colo). Distilled water is used in the experiments.

An alternative dual-inlet and dual-outlet pump configuration was also considered during the experimental design stage, however, we decided to use a simpler TCPC template to test and present results that are compatible with the existing literature that mainly examines single-IVC support. Single IVC support also allows for experimental simplicity in the mock-up circuit, whereas a dual-inflow/outflow pump would require a more cumbersome bypass circuit (to switch between TCPC and the TCPC-pump support), which would introduce additional resistance. With excessive resistance in the mock-up circuit, it would be challenging to show the benefits supplied by our device. Furthermore, for some patient groups it might still be more practical to provide IVConly support instead of interfering with the entire TCPC pathway or establishing multiple end-to-side anastomoses.

\section{SUPPLEMENTARY RESULTS \\ Effect of Rotational Speed}

During mock-up experiments, the impeller speed was found to be an important index of system performance. For the iATVA system (prototype 3), an aortic steal range of 0.95 to 1.35 LPM is studied at the adult hemodynamic conditions (see Figure E4). In this case the IVC flow rate varies between 2.4 and 1.5 LPM and the SVC current is between 1.6 and 2.6 LPM. The impeller speed of the pump is approximately $450 \mathrm{rpm}$ at $1 \mathrm{LPM}$ turbine flow in $60 \%$ IVC and $40 \%$ SVC region (red region) for physiological values. When the IVC flow is reduced and physiological values are exceeded, the impeller speed increases with higher turbine 
flow rates.; a 10\% increase in turbine flow rate results in a $20 \%$ change in impeller speed. As expected, SVC flow decreased as the IVC flow increased because of opposing pump pressure. These results show that a dual-inlet/dualoutlet pump configuration is a more practical alternative than IVC-only support, which would also be supported by the turbine and should be considered for future iATVA device prototypes.

\section{Comparative Performance of iATVA Prototypes}

In Figure 6, all 3 iATVA prototypes (P1, P2, and P3) are compared, which showed improved performance as the design evolved. Compared with P1 (6 blades and 3-LPM design flow rate), P2 (6 blades and 1.8-LPM design flow rate) resulted in significantly lower $\Delta \mathrm{P}$ because of high IVC flow capacity. Likewise, the additional turbine blades of version P3 provided some improvement. Overall, a positive pressure difference of approximately $1 \mathrm{~mm} \mathrm{Hg}$ is recorded between the P1 and P3 designs because of improved impulse speeds at the volute.

On the basis of the in vitro experiments using the TCPC pulsatile mock-up circuit, all 3 prototypes show a positive venous pressure decrease $(\Delta \mathrm{P}>0)$ beyond a relatively low critical rotational speed of 500,550 , and $660 \mathrm{rpm}$ for $\mathrm{P} 3$, P1, and P2, respectively. P1 as well as P3 provide approximately a 4-mm $\mathrm{Hg}$ differential pressure at $660 \mathrm{rpm}$, whereas the same pressure difference is obtained at a speed of $800 \mathrm{rpm}$ for the $\mathrm{P} 2$ design. These $\Delta \mathrm{P}$ levels correspond well with the steady test performance obtained for approximately a 1-LPM turbine current. The negative venous pressure effect $(\Delta \mathrm{P}<0)$ is also observed when the iATVA turbine inlet head does not have enough power to provide adequate torque.

\section{E-References}

E1. Tuzson J. Centrifugal Pump Design. Hoboken, New Jersey: John Wiley \& Sons; 2000.

E2. Sulzer Pumps Ltd. Centrifugal Pump Handbook. 3rd ed. Oxford, UK: Butterworth-Heinemann; 2010.

E3. Throckmorton AL, Ballman KK, Myers CD, Frankel SH, Brown JW, Rodefeld MD. Performance of a 3-bladed propeller pump to provide cavopulmonary assist in the failing Fontan circulation. Ann Thorac Surg. 2008;86:1343-7.

E4. Lacour-Gayet FG, Lanning CJ, Stoica S, Wang R, Rech BA, Goldberg S, et al. An artificial right ventricle for failing fontan: in vitro and computational study. Ann Thorac Surg. 2009;88:170-6.

E5. Rodefeld MD, Boyd JH, Myers CD, LaLone BJ, Bezruczko AJ, Potter AW, et al. Cavopulmonary assist: circulatory support for the univentricular Fontan circulation. Ann Thorac Surg. 2003;76:1911-6; discussion 1916.

E6. Rodefeld MD, Coats B, Fisher T, Giridharan GA, Chen J, Brown J, et al. Cavopulmonary assist for the univentricular Fontan circulation: von Karman viscous impeller pump. J Thorac Cardiovasc Surg. 2010;140:529-36.

E7. Chu MW, Sharma K, Tchervenkov CI, Jutras LF, Lavoie J, Shemie SD, et al. Berlin heart ventricular assist device in a child with hypoplastic left heart syndrome. Ann Thorac Surg. 2007;83:1179-81.

E8. Myers CD, Mattix K, Presson RG Jr, Vijay P, Maynes D, Litwak KN, et al. Twenty-four hour cardiopulmonary stability in a model of assisted newborn Fontan circulation. Ann Thorac Surg. 2006;81:264-70; discussion 270-1.

E9. Wei X, Sanchez PG, Liu Y, Li T, Watkins AC, Wu ZJ, et al. Mechanical circulatory support of a univentricular Fontan circulation with a continuous axial-flow pump in a piglet model. ASAIO J. 2015;61:196-201.

E10. Derk G, Laks H, Biniwale R, Patel S, De LaCruz K, Mazor E, et al. Novel techniques of mechanical circulatory support for the right heart and Fontan circulation. Int J Cardiol. 2014;176:828-32.

E11. Wermelt JZ, Honjo O, Kilic A, van Arsdell G, Gruenwald C, Humpl T. Use of a pulsatile ventricular assist device (Berlin heart EXCOR) and an interventional lung assist device (Novalung) in an animal model. ASAIO J. 2008;54:498-503. 


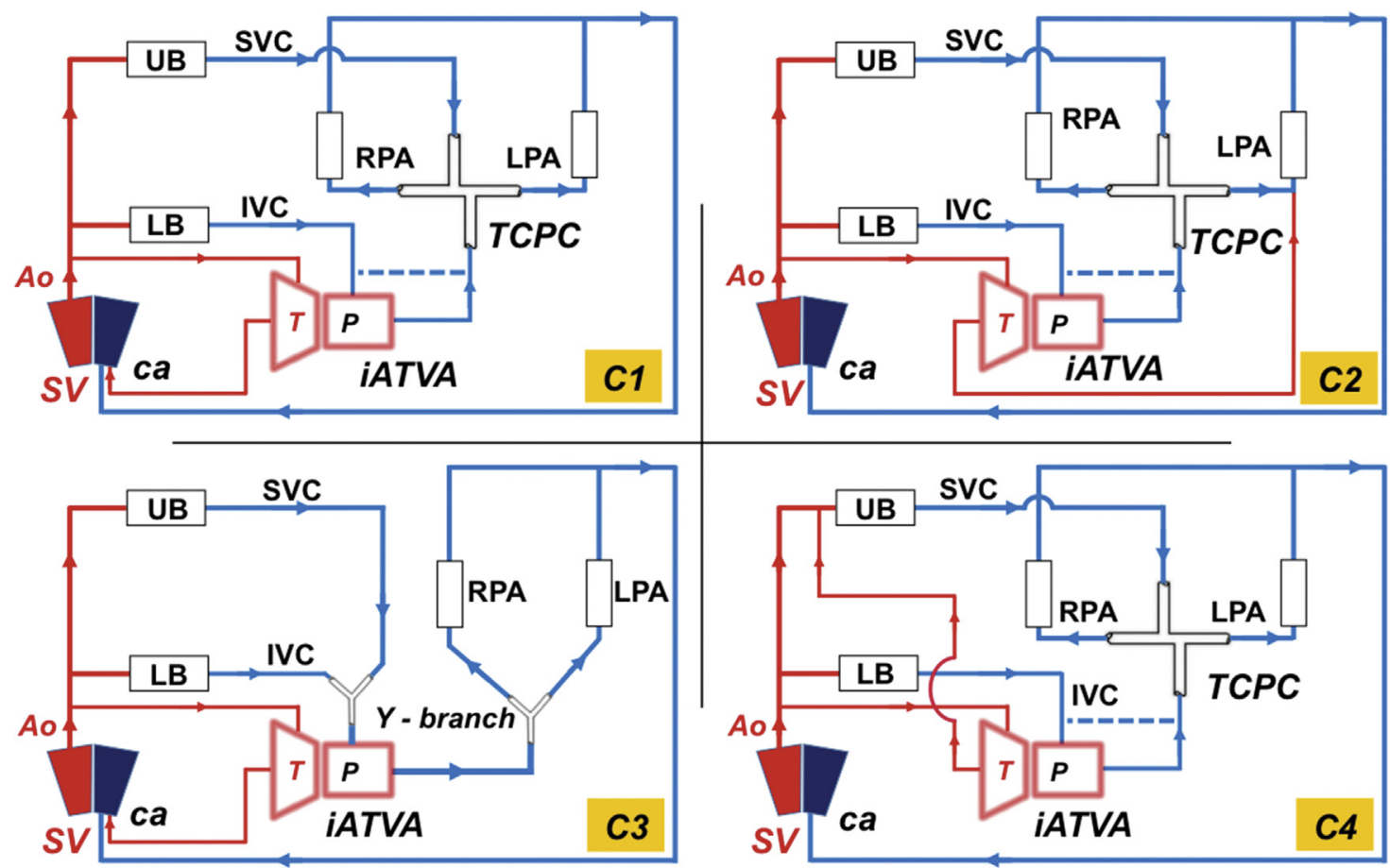

FIGURE E1. Different iATVA configuration alternatives schematically illustrated. All alternatives are implanted in the single ventricle ( $\mathrm{SV}$ ) circulation. Configurations 1, 2, and 4 vary in terms of the blood turbine outlet drainage location. This study investigated configuration $1(\mathrm{Cl})$ whereby the blood turbine outlet is drained to the common atrium $(c a)$. Configuration $2(C 2)$ drains to the distal of the pulmonary artery. Configuration $4(C 4)$ drains proximal to the axillary artery. Configuration $3(C 3)$ illustrates a double-inlet double-outlet venous pump configuration without a total cavopulmonary connection (TCPC). Note that there is no oxygen desaturation in iATVA configurations. $U B$, Upper body systemic bed; $S V C$, superior vena cava; $R P A$, right pulmonary artery; $L P A$, left pulmonary artery; $L B$, lower body systemic bed; IVC, inferior vena cava; Ao, aorta; iATVA, integrated aortic-turbine venous-assist. 


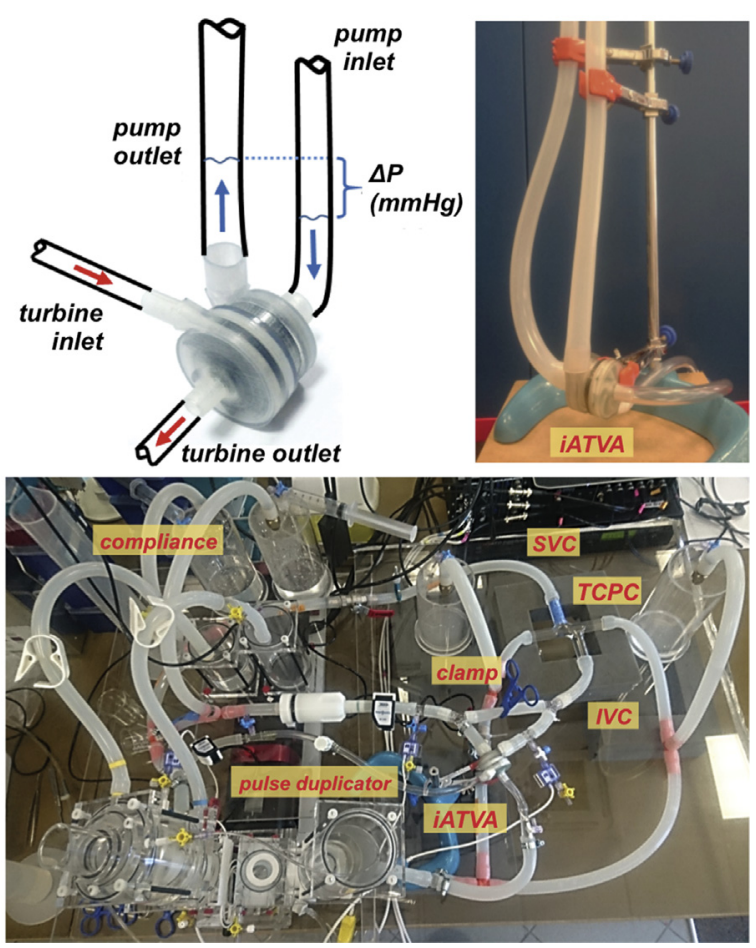

FIGURE E2. Steady and pulsatile flow experiments. Measurement locations and iATVA connection ports are illustrated in top left illustration, corresponding to the steady flow set-up, which allows the static pressure head measurements of the venous pump at different steady aortic steal levels (top right). The iATVA was introduced in the mock-up single-ventricle circuit featuring an idealized glass TCPC replica (bottom row). The mock-up system flow rate was set by the pulse duplicator by adjusting stroke and stroke volume. Desired pressure level was maintained by changing the IVC and SVC resistances. Pulsatile pressure measurements were acquired from the aortic outlet and the iATVA pump/turbine inlets and outlets. Pulsatile flow measurements were acquired from the IVC, SVC, and turbine inlet/ outlet and pump outlet. Turbine impeller speed was measured for each flow rate using a tachometer. The Y-connection established a parallel bypass circuit, which allowed for easy switching between the singleventricle circulation with and without iATVA devices. See also Video 1, recorded during the experiments. $\triangle P$, Net venous pressure augmentation provided by the pump impeller; iATVA, integrated aortic-turbine venousassist; $S V C$, superior vena cava; $T C P C$, total cavopulmonary connection; $I V C$, inferior vena cava. 

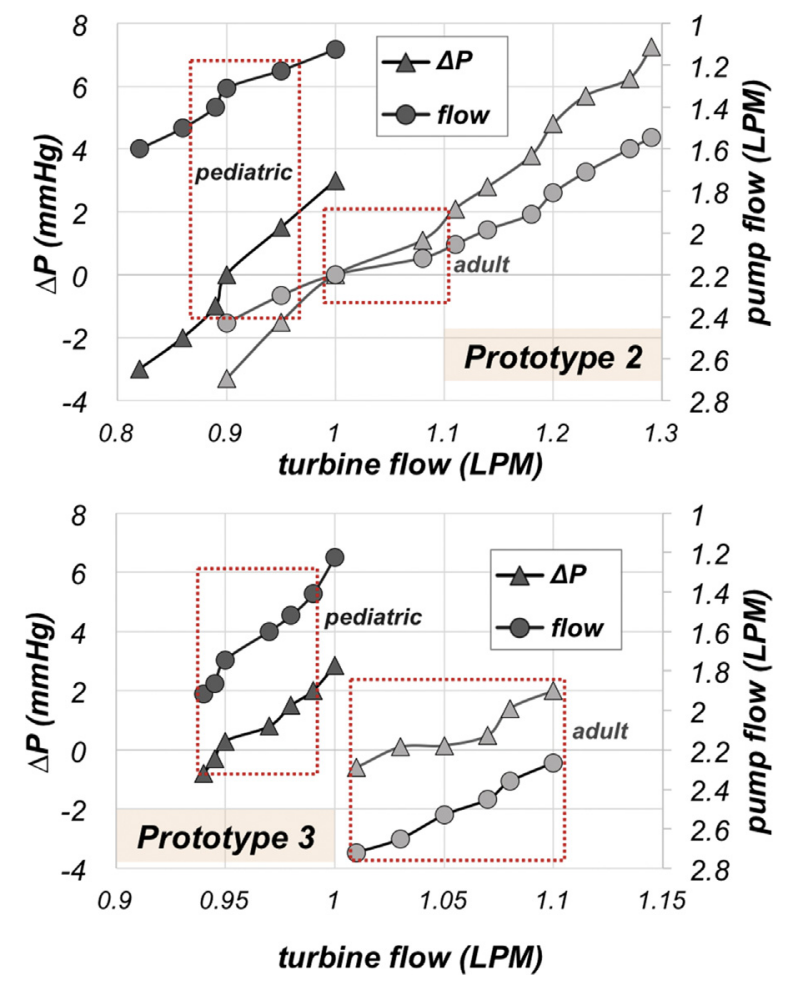

FIGURE E3. Venous pump flow (through the IVC) and venous pressure augmentation $(\Delta \mathrm{P})$ characteristics for iATVA prototype 2 (top chart) and prototype 3 (bottom chart) obtained from the pulsatile mock-up singleventricle circulation flow loop. For both prototypes pediatric and adult operation modes corresponding to 3.5 and 5 LPM total cardiac output are tested, respectively (displayed in the red boxes). Average values of pulsatile waveforms are plotted after the iATVA is implanted in the single-ventricle circulation system. $\Delta P$, Net venous pressure augmentation provided by the pump impeller; $L P M$, liters per minute.

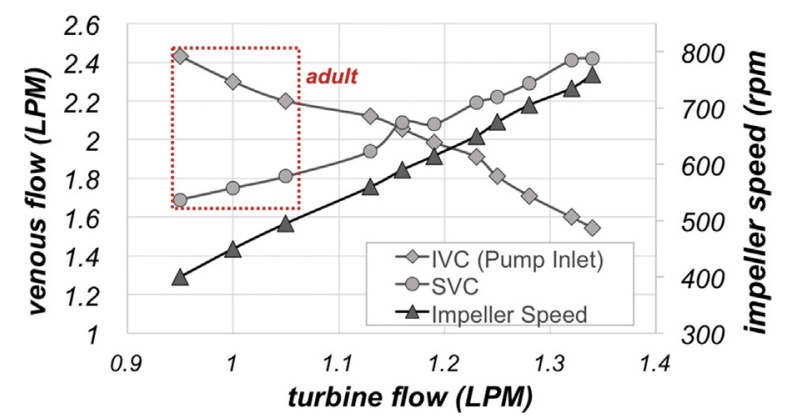

FIGURE E4. For the adult Fontan hemodynamic conditions, iATVA mock-up pulsatile test results at physiological (indicated by the red box) and off-design operating conditions spanning 80 to $150 \mathrm{~mm} \mathrm{Hg}$ mean aortic pressure are plotted. Only prototype 3 results are presented as trends were similar for all iATVA prototypes. Mean values for the venous flow (through the IVC pump), impeller speed, and turbine flow rates are plotted. $L P M$, Liters per minute; $I V C$, inferior vena cava; $S V C$, superior vena cava.

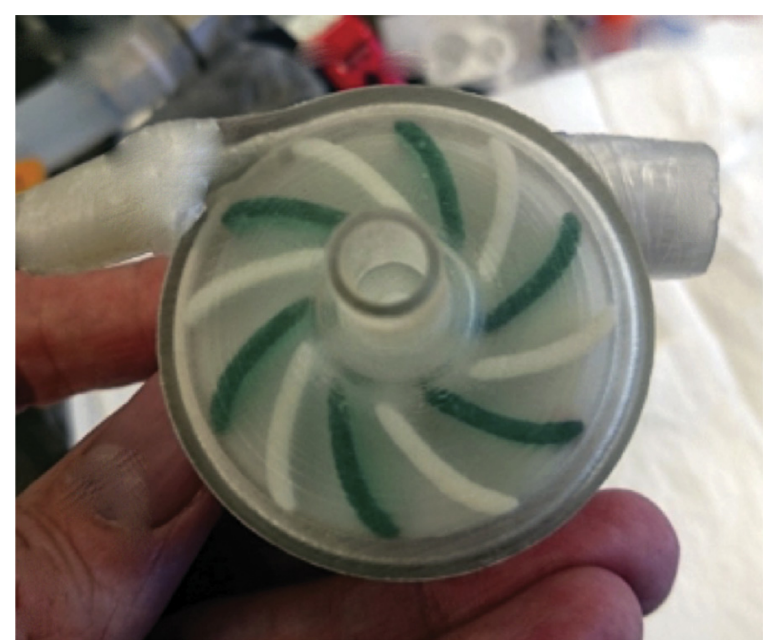

FIGURE E5. A close-up picture of the turbine impeller and shroud of the iATVA prototype 3 is presented. Six additional blades are produced separately using a high-accuracy 3-D micro stereolithography printer (Projet 1200; 3D Systems, Rock Hill, SC) from VisiJet FTX Green resin (3D Systems) and glued to the prototype 1 impeller. A total of 3 iATVA prototypes are tested in static as well as dynamic conditions. 

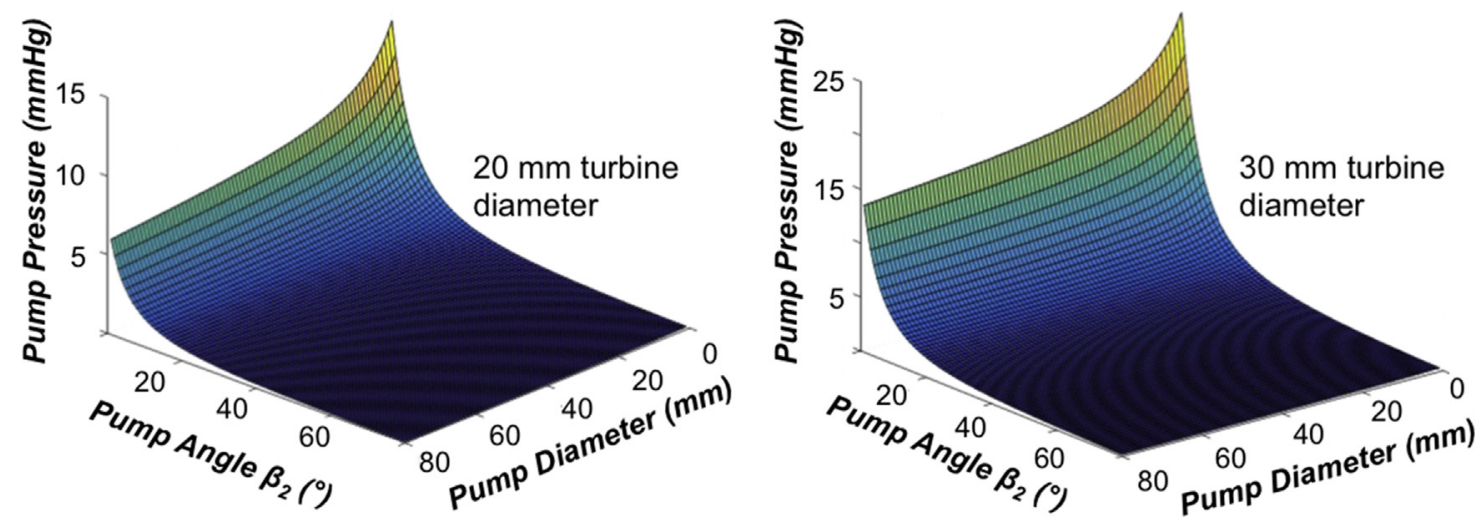

FIGURE E6. Ideal characteristics of the iATVA system estimated from turbomachinery theory for 2 further miniaturized turbine impeller sizes of 20 and $30 \mathrm{~mm}$. The total mechanical power transfer efficiency is 0.50 ; total cardiac output is $5 \mathrm{LPM}$; turbine aortic steal is $10 \%$ and inferior vena cava pump flow is 3.5 LPM.

TABLE E1. Average operating points (mean venous pressure decrease and flow rate values) of existing single-ventricle devices intended to support Fontan circulation are compared with the new iATVA prototypes

\begin{tabular}{|c|c|c|c|c|}
\hline Pump design & $\begin{array}{c}\text { Venous pressure } \\
\text { decrease, } \mathbf{m m ~} \mathbf{H g}\end{array}$ & Flow rate, LPM & Impeller speed, rpm & Notes \\
\hline Propeller ${ }^{\mathrm{E} 3}$ & 5 to 50 & 0.5 to 3.5 & 5000 to 7000 & $\begin{array}{l}\text { Hydraulic in vitro and simulation } \\
\text { performance }\end{array}$ \\
\hline $\mathrm{Axial}^{\mathrm{E} 4}$ & 5 to 20 & 2 & 1700 to 4500 & Failing Fontan \\
\hline $\mathrm{Axial}^{\mathrm{E} 5}$ & 2.4 & 3.7 & No information & \\
\hline No impeller blades ${ }^{\mathrm{E} 6}$ & 5 to 20 & 0 to 5 & 0 to 7000 & $\begin{array}{l}\text { Dual IVC/SVC support, } \\
\text { mock-up flow loop }\end{array}$ \\
\hline Berlin heart ${ }^{\mathrm{E} 7}$ & No information & 3.8 & 80 Strokes/min & Hypoplastic left heart patient \\
\hline iATVA, present study & 5.7 & 5 & 705 & IVC support \\
\hline Centrifugal $^{\mathrm{E} 8}$ & 10 & No information & No information & \\
\hline Axial $^{\mathrm{E9}}$ & 12 & 3.1 to 1.2 & 18,000 to 24,000 & Piglet model \\
\hline Axial $^{\mathrm{E} 10}$ & 7 & 4.6 & 10,000 & Jarvik VAD \\
\hline
\end{tabular}

All existing devices require external drive power. $L P M$, Liters per minute; $I V C$, inferior vena cava; $S C V$, superior vena cava; iATVA, integrated aortic-turbine venous-assist; $V A D$, ventricle assist device. 
TABLE E2. Main design parameters of 3 iATVA prototypes (P1, P2, and P3) are summarized

\begin{tabular}{lcc}
\hline & Turbine & Pump \\
\hline Flow rate, LPM & 0.5 (aortic steal) & $3.0 \mathrm{P} 1,1.8 \mathrm{P} 2,3.0 \mathrm{P} 3$ \\
Blade height, $\mathrm{mm}$ & 5 & $9 \mathrm{P} 1,4.5 \mathrm{P} 2,9 \mathrm{P} 3$ \\
$\begin{array}{l}\text { Impeller } \\
\text { diameter, } \mathrm{mm}\end{array}$ & 38 & 32 \\
Blade angle, $\beta_{2}$ & $75^{\circ}$ & $60^{\circ}$ \\
Number of blades & $6 \mathrm{P} 1,6 \mathrm{P} 2,12 \mathrm{P} 3$ & 5 \\
\hline $\begin{array}{l}\text { Shroud volume, } \mathrm{cm}^{3} \\
1.1 \mathrm{P} 1,1.1 \mathrm{P} 2,0.5 \mathrm{P} 2\end{array}$ & $12.6 \mathrm{P} 1,11.5 \mathrm{P} 2,11.5 \mathrm{P} 2$ \\
\hline \begin{tabular}{l} 
Volute volume, $\mathrm{cm}^{3}$ \\
\hline Diff
\end{tabular} & 1.16 & $3.1 \mathrm{P} 1,2.0 \mathrm{P} 2,2.0 \mathrm{P} 2$ \\
\hline
\end{tabular}

Differences between iATVA versions are the turbine blade numbers and pump volute size. The flow rate specification that defines the turbine section shape is kept the same for all 3 designs to steal less from the aortic current (0.5 LPM). Physiologic IVC flow rates corresponding to baseline pediatric and adult hemodynamics are used. $L P M, \mathrm{Li}$ ters per minute.

TABLE E3. Summary of hemodynamic measurements obtained during the pulsatile mock-up single-ventricle flow loop experiments

\begin{tabular}{lccccc}
\hline & \multicolumn{2}{c}{ TCPC state-shunt } & \multicolumn{2}{c}{ TCPC + iATVA } \\
\hline Stroke column, mL & 60 & 67 & 60 & 67 & 51 \\
SVC flow rate, $\mathrm{LPM}$ & $1.1(0.006)$ & $1.1(0.002)$ & $1.02(0.001)$ & $1.11(0.01)$ & $0.88(0.002)$ \\
\hline IVC flow rate, $\mathrm{LPM}$ & $2.16(0.001)$ & $2.16(0.002)$ & $2.17(0.001)$ & $2.27(0.002)$ & $1.7(0.002)$ \\
Aortic pressure, $\mathrm{mm} \mathrm{Hg}$ & $94(13)$ & $114(18)$ & $96(15)$ & $114(19)$ & $71(13)$ \\
Venous pressure, mm Hg & $18.6(1.1)$ & $16.6(1.0)$ & $10.8(0.8)$ & $11.5(0.8)$ & $10.5(0.8)$ \\
PA pressure-pump outlet, $\mathrm{mm} \mathrm{Hg}$ & $13.4(0.9)$ & $9.8(0.7)$ & $12.2(0.8)$ & $12.9(1.2)$ & $12.0(0.6)$ \\
\hline
\end{tabular}

Here an alternative experimental protocol is used to study systemic pressure regulation through stroke volume adjustment instead of systemic vascular resistance modulation. The later mode is already presented in Table 1. In this experiment, the venous pump and the turbine is stopped using a thin wire catheter to represent the TCPC state-shunt. Removal of the wire allowed instantaneous switching to the venous support mode; TCPC + iATVA, without any change in aortic pressure, turbine flow (1.0-1.2 LPM), heart rate, stroke volume, or resistance adjustment (because the turbine shunt is operational, but producing no pump work due to the wire catheter at the TCPC state-shunt). According to the experimental protocol, first the TCPC state is established as in Table 1, and then the iATVA device with the thin wire that immobilizes the common shaft is introduced. This reduced the systemic pressure, which is adjusted back to the initial TCPC state levels by increasing the stroke volume (instead of SVR) leading to the TCPC state-shunt. Removal of the wire catheter resulted the TCPC + iATVA hemodynamics without changing the stroke volume where turbine power is now transferred to the pump side freely, and venous pressure decrease is recorded. This protocol is applied to 3 different stroke volumes. Values are provided for prototype 3 at constant heart rate ( 70 beats per minute) and correspond to pediatric physiological conditions with variable stroke volume. Mean and pulsatile amplitudes (in parenthesis) of the waveforms are presented. TCPC, Total cavopulmonary connection; iATVA, integrated aortic-turbine venous-assist; SVC, superior vena cava; $L P M$, liters per minute; IVC, inferior vena cava; $P A$, pulmonary artery. 